\title{
Fractures of metacarpal bone: evaluation of functional outcome of open reduction and internal fixation with mini locking plate: a hospital based study
}

\author{
Arumugam A. Kandasamy ${ }^{1}$, Mozammil Pheroz ${ }^{2}$, Arvind Kumar ${ }^{2}$, L. G. Krishna ${ }^{2}$, \\ Ankit Jain', Rahul Grower ${ }^{2}$
}

\begin{abstract}
${ }^{1}$ Sports Injury Centre, ${ }^{2}$ Central Institute of Orthopaedics, Vardhaman Mahavir Medical College and Safdarjung Hospital, New Delhi, Delhi, India
\end{abstract}

Received: 01 April 2019

Accepted: 20 April 2019

\section{*Correspondence:}

Dr. Mozammil Pheroz,

E-mail: muzammilphrz@gmail.com

Copyright: ( $\odot$ the author(s), publisher and licensee Medip Academy. This is an open-access article distributed under the terms of the Creative Commons Attribution Non-Commercial License, which permits unrestricted non-commercial use, distribution, and reproduction in any medium, provided the original work is properly cited.

\begin{abstract}
Background: Metacarpal bones fracture is very common. Management of metacarpal fractures varies from conservative to percutaneous pinning to various surgical methods. We endeavour to evaluate the functional outcome of metacarpal fractures in patients managed with open reduction and internal fixation with mini locking plate.

Methods: A total of 32 patients with extra-articular metacarpal bones fracture were recruited for the study. After open reduction the fractures were fixed with the mini locking plate, postoperative day 3 , plaster removed and active and passive exercises started. The Michigan hand score was used for functional evaluation, grip strength, visual analogue scale score, range of motion evaluated at follow up till six months.

Results: All the 32 patients achieved union, 31 had full union at 6 weeks whereas 1 patient has delayed union. The Michigan hand outcome questionnaire score of $97.5 \%$ at 6 months in all 32 patients. A total of 5 out of 32 patients had complications, the most common being finger stiffness followed by superficial infection and delayed union.

Conclusions: We concluded that metacarpal plating with mini locking plate is a good option to achieve and maintain a rigid fixation and this method produces a better outcome in unstable fractures of metacarpal bones.
\end{abstract}

Keywords: Metacarpal bones, Locking plates, Michigan hand outcome questionnaire score

\section{INTRODUCTION}

Hand is one of the most important organs in the human body. It helps to interact with the world around us. It is a complex tool that has multiple joints and different tendons and ligaments attached to it. Fractures around hand approximately account for $10 \%$ of all the fractures reporting to the emergency-room and outpatients department, $36 \%$ of all the hand fractures are metacarpal fractures. ${ }^{1}$ Majority of traumatic metacarpal fractures are work related, and most of the affected individuals belong to younger age group. ${ }^{2}$ Proper management of metacarpal fractures is of utmost importance as any complication can result in functional handicap. ${ }^{3}$ Hand plays a pivotal role in a person's day to day life and it becomes really important to aim to reduce the complication and enhance union of bone so that the patient can return to his full, preinjury level activities as early as possible. Complications happen mostly because of two reasons, first-intraoperative, due to injury to the joint and second due to prolonged immobilization. Depending upon nature of injury and type of fractures, metacarpal fractures can be treated by various methods that range from conservative treatment by closed reduction and casting/slab to close reduction and percutaneous pinning to external fixation to open reduction and internal fixation with plates and screws or screws alone. ${ }^{4}$ Conservative treatment with close reduction and casting is not suitable 
for unstable fractures and it requires prolonged immobilization that ultimately results in stiffness of fingers and wrist as well. K-wiring provides chances for early mobilization but at the same time it can't give rotational stability, produces stiffness at metacarpophalangeal and carpometacarpal joint plus it is not suitable an option for comminuted fracture. ${ }^{5}$ Open reduction and fixation using a locked plate provides accurate reduction and rigid fixation and ensures an early mobilization. ${ }^{6}$ Thus this method avoids joint stiffness and provides better rotational stability and earliest rehabilitation. From the literature available, it can be easily make out that there is a shift from conservative management to surgical treatments as it helps in proper maintenance of hand function.

Through this study, we endeavor to evaluate the functional outcomes of open reduction and internal fixation of metacarpal bones fracture using mini locking plates.

\section{METHODS}

This was a prospective study, conducted between August 2016 to April 2018 at Central Institute of Orthopaedics, Safdarjung Hospital, New Delhi, India. The study was approved by the ethical committee of the Institution. A total of 32 patients presenting to the emergency and Out Patients Department, were recruited for the study after they fulfilled the inclusion criteria.

Inclusion criteria: All consenting patients more than 18 years age having closed metacarpal bone fractures with discontinuity or disruption of more than $50 \%$ shaft or neck, trauma less than 2 weeks old, multiple metacarpals in the same hand considered as a single case.

Exclusion criteria: Not giving consent, previously injured hand, pathological fracture, rheumatoid arthritis or any deforming bony disorders, co-morbid metabolic disorders, paralytic hand, infected/compound fractures and fractures having intra-articular components.

\section{Surgical steps}

The surgery was done either under general anaesthesia or axillary nerve block, the patient kept in supine position and parts were cleaned, prepared and draped from mid arm to whole of hand and tourniquet inflated. Dorsal approach to the hand was used. A linear or slightly curved incision was made over the dorsal aspect of hand over the metacarpal to be operated (for fixation of two adjacent metacarpals, incision centered between that two metacarpals is preferred). The dorsal sensory branches and superficial veins must be protected. Extensor tendons are retracted with surrounding loose connective tissue. Fracture site was exposed. Intervening soft tissue cleared off from the fracture site. Fracture ends curetted well. Reduction attempted. Once the reduction is achieved it is held in place with bone holding or plate holding forceps, locking plate is fixed over the dorsal surface of metacarpal with screws. The plate is covered with periosteum and soft tissue, subcutaneous plane and skin closed in layers.

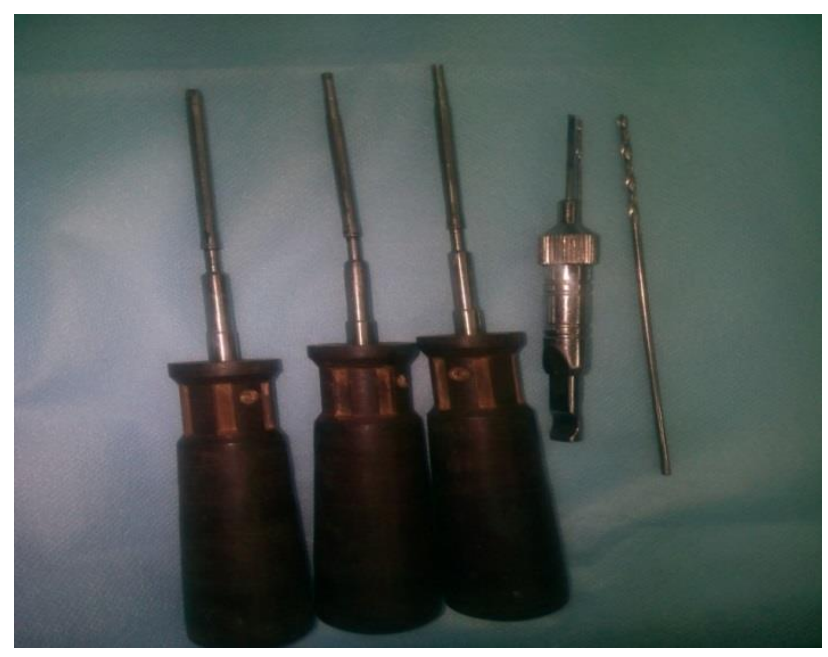

Figure 1: Instruments used in the surgery.

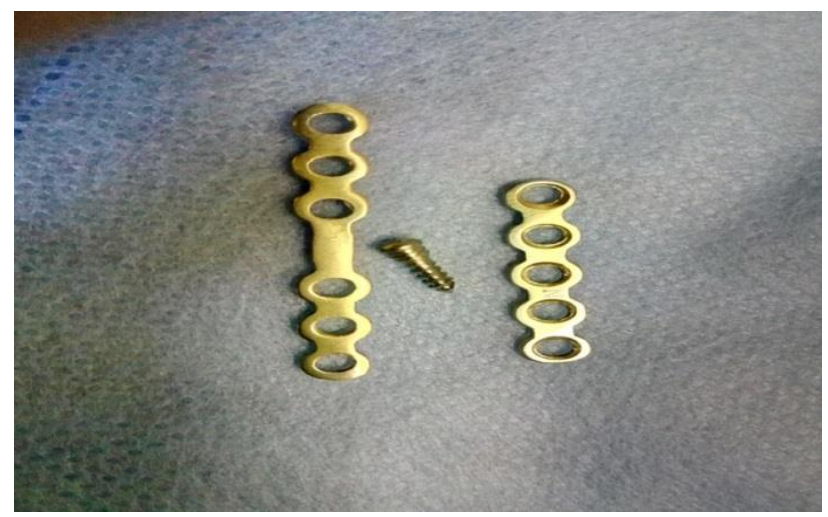

Figure 2: Mini-locking plates and screw.

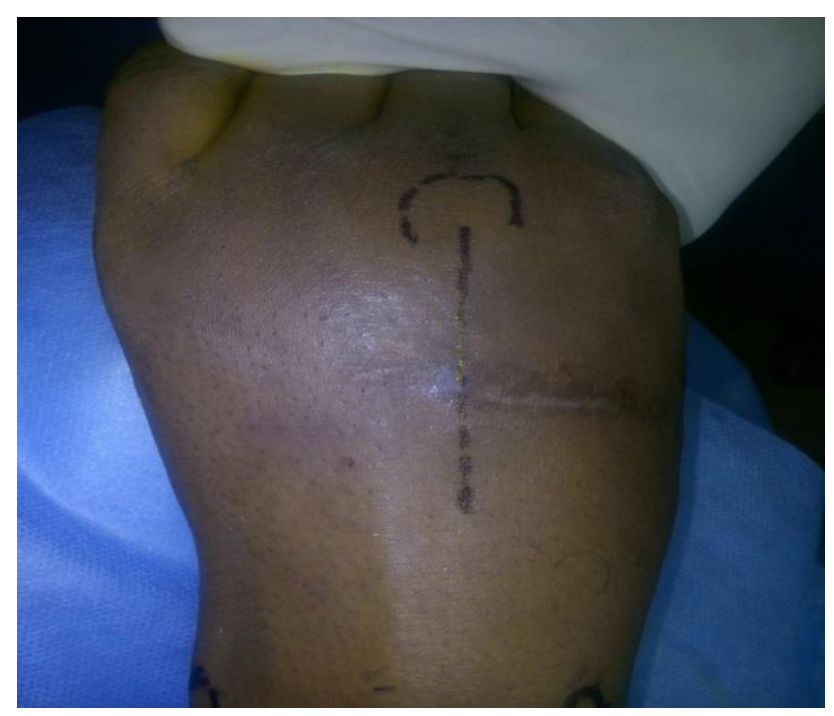

Figure 3: Surface-marking for dorsal incision for metatarsal fracture fixation. 

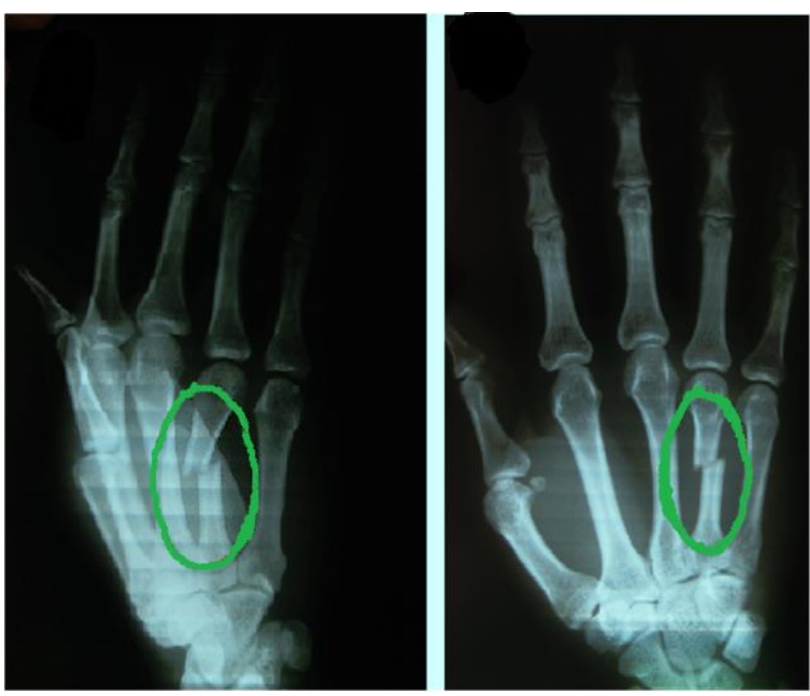

Figure 4: Preoperative X-rays of fractured fourth metatarsal.

\section{Physiotherapy and rehabilitation}

Postoperative day 3, first dressing done and intermittent exercises started according to the allowable limits of the patient. Plaster slab was removed completely at day 7 and full active and passive exercises are started. Surgical sutures were removed on day 15 .

\section{Follow up}

Patient was followed up post-surgery for clinical and functional assessment at 1 month, 3 months and 6 months. Radiographic follow up done at 6 weeks, 12 weeks and 6 months to assess the bony union.
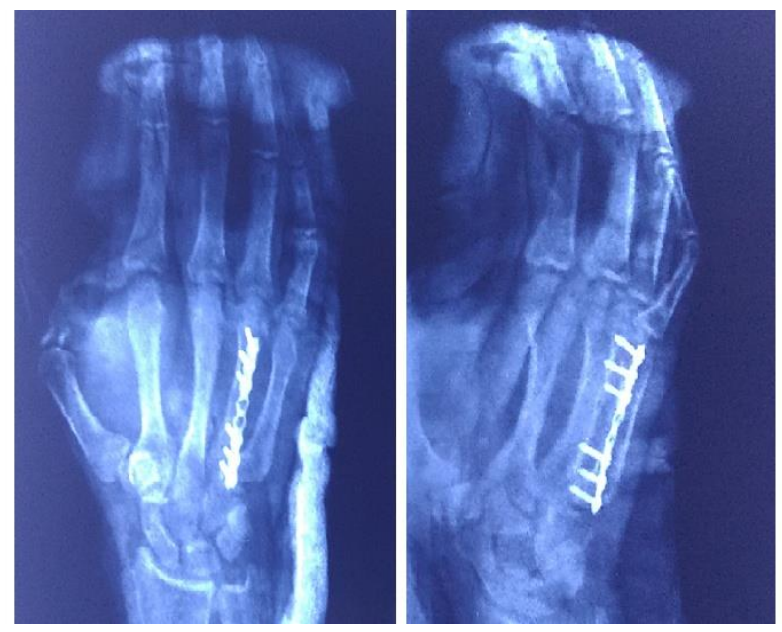

Figure 5: Postoperative X-ray.

\section{Data collection}

Demographic data related to the study population was recorded. Union was assessed using serial plane radiograph in two views namely anteroposterior and oblique. The functional outcomes were measured using the Michigan hand outcome questionnaire (MHQ) scores. $^{7}$ The MHQ contains six domains: overall hand function, activities of daily living, work performance, pain, aesthetics, and satisfaction. In the pain scale, high scores indicate greater pain, while in the other five scales, high scores denote better hand performance. The raw scale score for each of the six scales is the sum of the responses of each scale item. The raw score is converted to a score ranging from 0-100. The response category for one of the questions is reversed and recorded. For the Pain scale, a higher score indicates more pain. For the other five scales, higher scores indicate better hand performance.

Independently, the visual analogue scale (VAS) Score was recorded on a scale of 1 to 10. Hand grip was recorded using a dynamometer. The range of motion was also recorded.
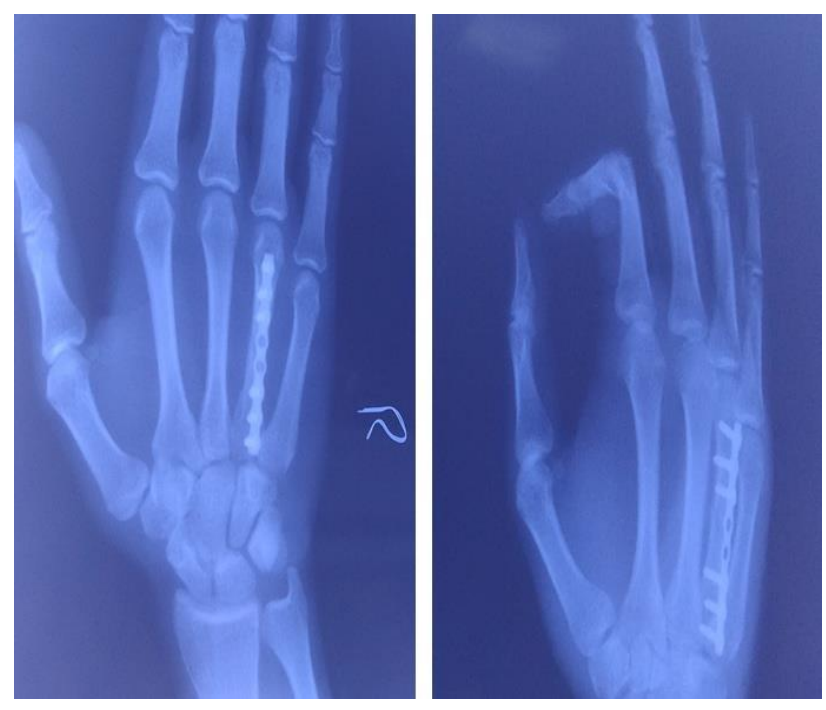

Figure 6: 6 weeks postoperative $X$-ray showing union in two views.
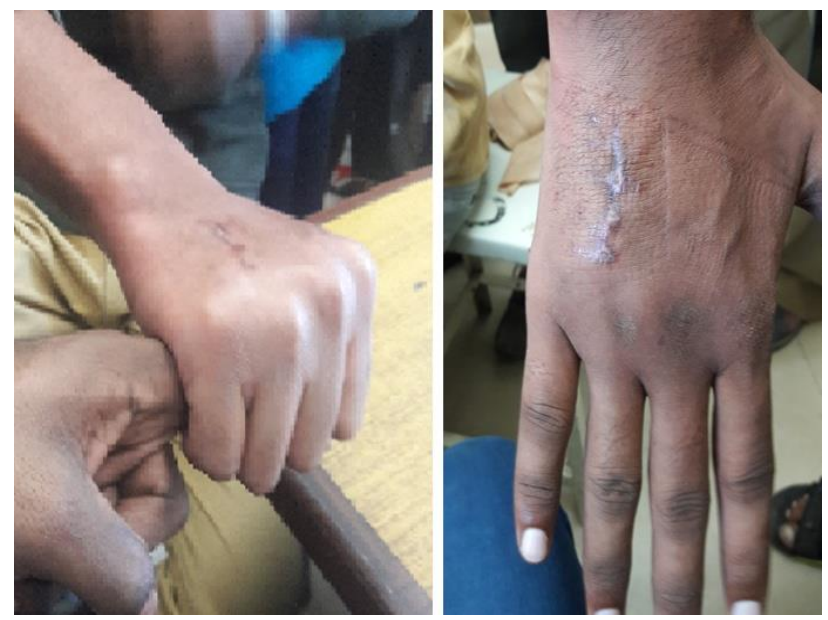

Figure 7: Clinical photograph showing range of motion (complete flexion-extension arc). 


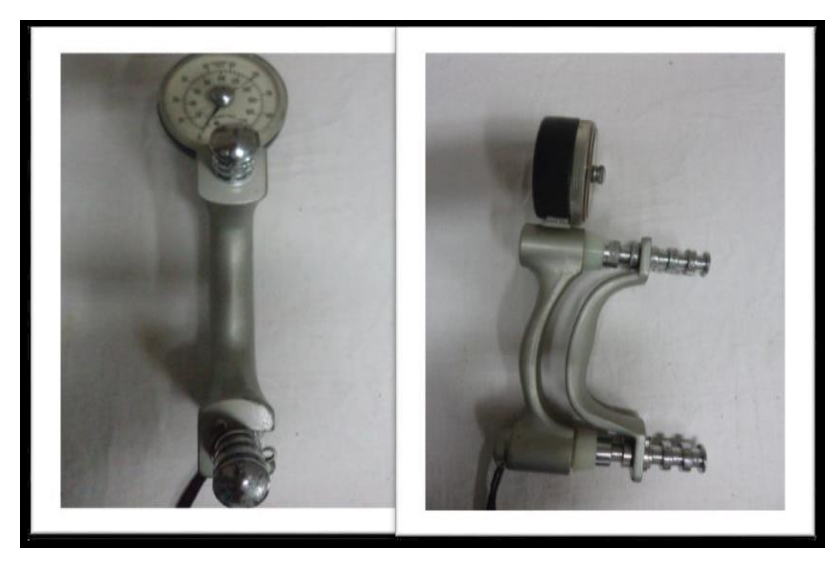

Figure 8: Dynamometer machine to measure grip strength.

\section{Statistical analysis}

Categorical variables were presented in number and percentage (\%) and continuous variables were represented as mean \pm Standard deviation (SD). Quantitative variables were compared using paired t-test between pre and post and for comparison between three groups, ANOVA was used and for two groups, independent $\mathrm{T}$ test was used. Qualitative variables were correlated using Chi-Square test/Fisher's exact test. A p value of $<0.05$ was considered statistically significant.

\section{RESULTS}

Out of the total 32 cases included in the study. 2 patients had multiple metacarpal fractures $(6.25 \%$ cases $)$. Mean age of the study population was 32.75 years with minimum of 19 years and maximum 65 years of age. Dominant hand was involved in 20 (18 right and 2 left) of the patients $(62.5 \%) .26$ out of 32 were male patients (approximately $81.25 \%$ ). All the 32 patients who underwent open reduction and internal fixation with mini locking plate had a bony union (100\%). 31 patients showed radiological union at 6 weeks and 1 patient had delayed union but at the final follow up at 6 months all cases achieved complete union. Type of fracture appeared to be a factor in union. Spiral and oblique fractures united at 6 weeks, the two fractures that were having transverse and comminuted morphology took a longer time to unite. Functional outcome assessed by Michigan hand outcome questionnaire score. At 1 month mean MHQ was 81.3 with a range of (77-87), which improved to 91.75 at 3 months and finally at 6 months the mean MHQ score was 97.65 with a range of (96-100).

Independent assessment of pain using visual analogue score was done and it was found that patient had a significant improvement in pain from a mean preoperative level of 6.40 (range 5-8), to 2.31 (range 1-3) at 1 month to mean value of 0.34 (range $0-1$ ) at 6 months follow up. The range of motion (ROM) measured as extension to flexion at the metacarpophalangeal joint was improved in the follow-up. In our study out of 32 patients, at $6^{\text {th }}$ month postoperatively 26 patients had a good range of movement and rest 6 had some stiffness (restrictions in terminal range of motion). At 6 months the mean ROM in the study population was 87.8 degrees.

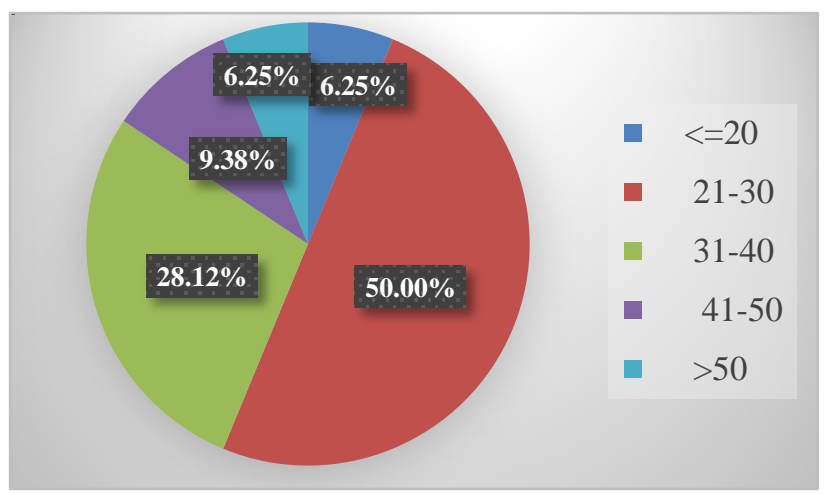

Figure 9: Age distribution of study population.

The average grip strength at 6 months was found out to be $36.4 \mathrm{~kg}$ with a range of $(20-53 \mathrm{~kg})$. Total 5 out of 32 $(15.6 \%)$ cases had some kind of complications. 2 had superficial infections with metacarpophalangeal joint stiffness, 2 patients had isolated metacarpophalangeal joint stiffness, 1 patient had delayed union.

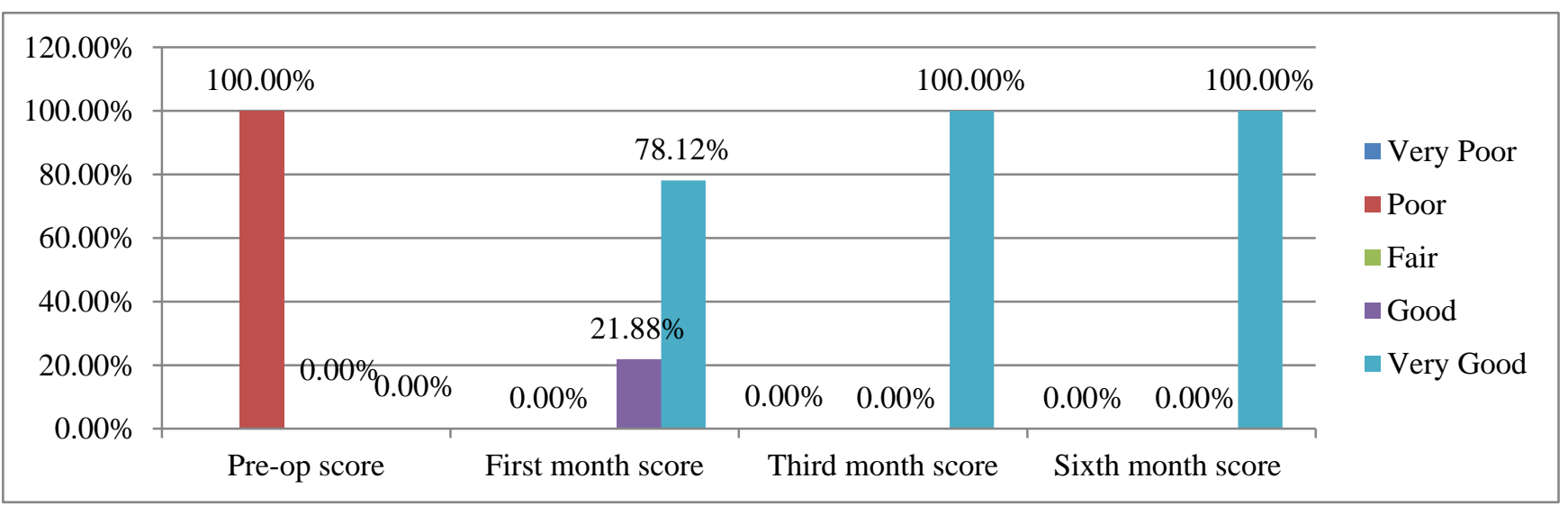

Figure 10: The Michigan hand outcome questionnaire score on each follow-up visit. 


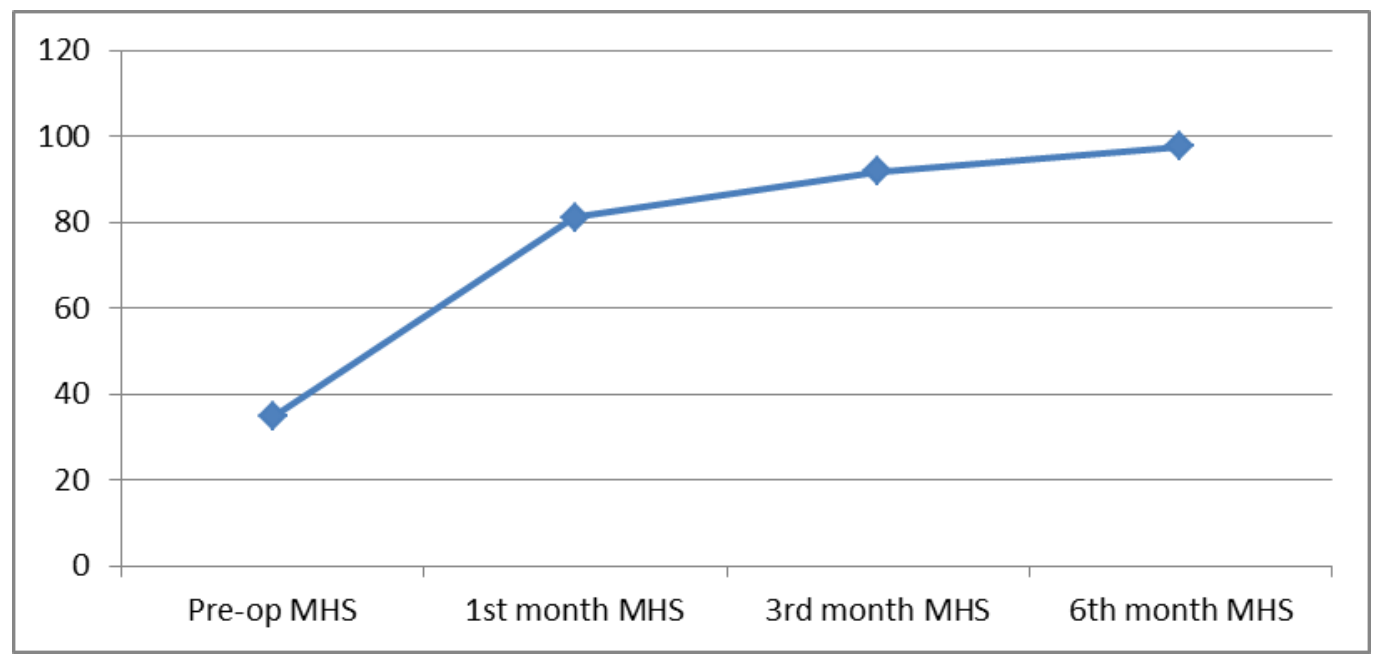

Figure 11: Line diagram showing MHQ trend with each follow-up visit.

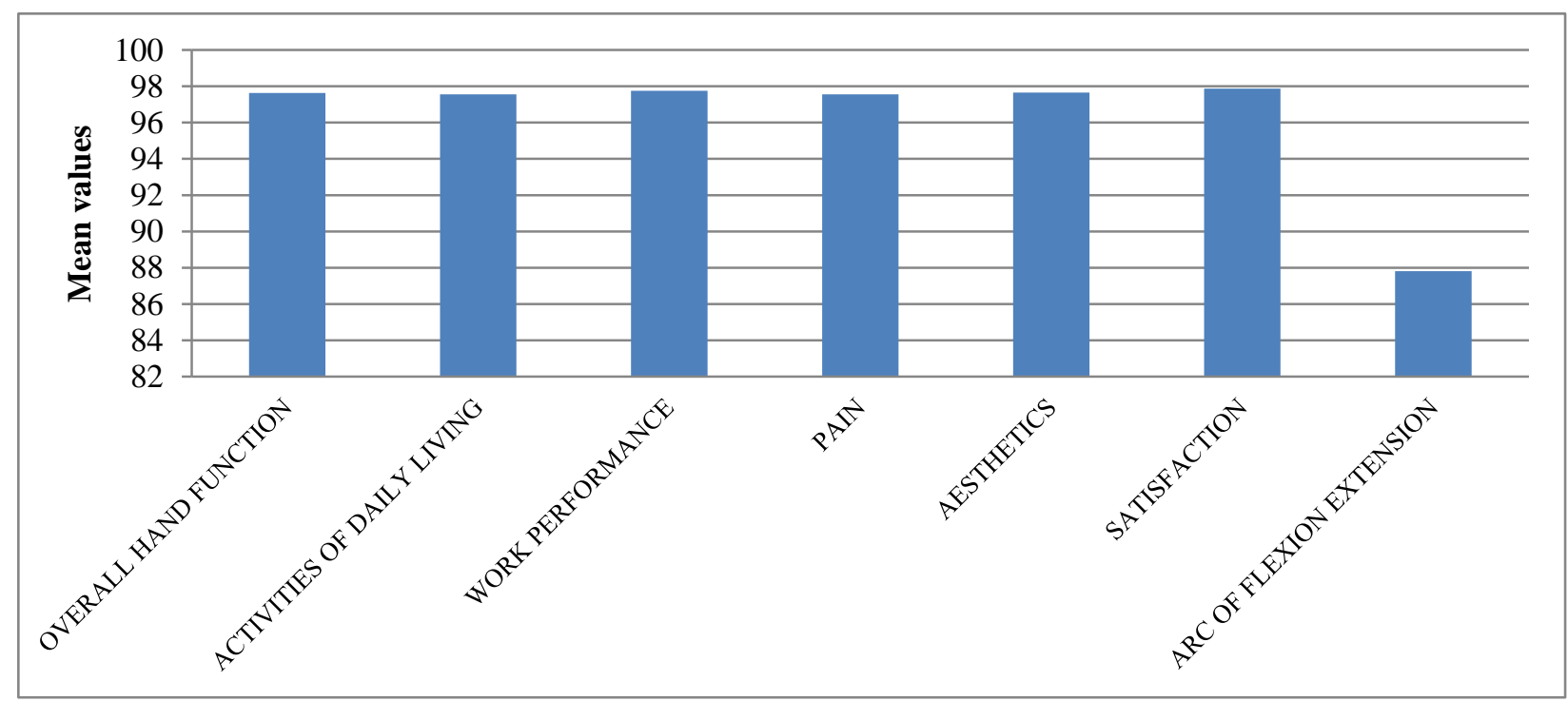

Figure 12: Functional assessment at the end of follow-up (6 months).

Table 1: Demographic and clinical characteristic of the patients in the study.

\begin{tabular}{|ll|}
\hline Characteristics & No $(\%)$ \\
\hline Age (range, years) & $32.75(19-65)$ \\
\hline Sex & $26(81.25)$ \\
\hline Male & $6(18.75)$ \\
\hline Female & $20(18$ right, 2 left $)(62.5)$ \\
\hline Side & $12(37.5)$ \\
\hline Dominant & \\
\hline Non-dominant & $13(40.6)$ \\
\hline Fracture type & $15(46.9)$ \\
\hline Transverse/short oblique & $4(12.5)$ \\
\hline Spiral & \\
\hline Comminuted & $22(68.8)$ \\
\hline Injury mechanism & $10(31.2)$ \\
\hline Direct trauma (striking person/objects) & $32(100)$ \\
\hline Indirect trauma (slip and fall, RTA) & \\
\hline Total (n) & \\
\hline
\end{tabular}




\section{DISCUSSION}

Being so common, metacarpal injuries are frequently encountered in Orthopaedic outpatient Department and emergency rooms. Most of the times these fractures are managed conservatively with plaster casting/slab. Surgical intervention is required for special situations like an unstable variety of fracture. Way back in the year, 1928 it was Lambotte who for the first time explained in detail regarding surgical treatment of fractures of metacarpals and other fractures around hand. ${ }^{8}$ Since Lambotte many techniques for metacarpal bone fracture fixation has been reported like intra-medullary k-wiring, transverse k-wiring, Bouquet techniques, cerclage, mini external fixators, screw fixation (lag principle) and fixation with plate and screws and many more. ${ }^{9}$ The principal goals of treatment are to restore hand grip and to improve the outcome of hand function. However, indications for conservative or surgical treatment of metacarpal fractures are not well defined in the literature. Surgery is usually indicated for the fractures that are having characteristics that may result in significant hand functional disability or cosmetic issues. Creating stability in an unstable fracture is the primary indication, although no concrete definition of unstable MC shaft fractures exists. ${ }^{9,10}$

Various studies have proved that operative time is shorter if an intramedullary pin is used, but a loss of reduction, penetration to the metacarpophalangeal joint and secondary surgery for hardware removal are higher in this group. ${ }^{9-11}$

Bouquet technique has been designed to address this shortcoming and has been used in fifth metacarpal with a good result. This is an effective method that helps us to fix the fracture without causing joint injury. ${ }^{12}$ But, this method is not suited for the fourth metacarpal due to its more central position in hand and metacarpal joint injury is inevitable if intramedullary nailing is applied for fourth metacarpal fracture. ${ }^{13}$

K-wiring is a popular method among orthopaedic surgeons worldwide for metacarpal bone fractures, and using a k-wire has a benefit as it can be used as a joystick to help in reducing fracture intra-operatively, however if the k-wire is not rigid enough it may lead to loss of reduction subsequently and may be complicated by pin tract infection or pin breakage. ${ }^{14}$ Also, K-wire doesn't appear to be a good choice for comminuted fractures and chances of metacarpophalangeal joint penetration is always there in the procedure.

Metacarpal screw fixation has been commonly used in the past but it doesn't produces satisfactory results in long oblique pattern of fracture or a fracture where gross comminution is there. ${ }^{15}$

External fixators can be used for comminuted fractures or in a situation with variable soft tissue loss or in a place where it is not possible to maintain the anatomical architecture of bone. But, it is not used in simple fractures of metacarpal bones. ${ }^{16-18}$

Various studies have compared functional and clinical results after plating with other methods of metacarpal fracture fixations using the MHQ scores. Hongyi et al when they compared results of plating versus K-wiring they reported that mean MHQ score was $96.7 \% .{ }^{19}$ In our study, the MHQ score was seen to be progressively improving at every follow up with a mean score of $97.65 \%$ at the end of follow up (at the end of the sixth month). This implies that postoperatively at the end of the first month, almost all patients showed quick and good improvement, then after, in $3^{\text {rd }}$ and $6^{\text {th }}$ month follow-up, patients showed good but gradually progressive improvement with a mean score of $97.65 \%$ (a very good score). This implies very good functional outcome of hand and patient-satisfaction after treatment with locking plate fixation. The mean range of motion (ROM) at metacarpophalangeal joint (an arc of flexion-extension) at $6^{\text {th }}$ month for 32 patients in our study is 87.8 degrees. Several other studies have reported a range of motion at final follow up as a mean value of 83.3 degrees after plating as compared to 72.2 degrees after $\mathrm{K}$ wiring. ROM after this procedure is excellent and this can be a preferable method of metacarpal fracture fixation compared to other measures like conservative slab or cast, K-wire fixation. The grip strength assessed with the help of a dynamometer at 6 months after surgery. ${ }^{20}$ Expressed in kilograms $(\mathrm{kg})$ the average was $36.4 \mathrm{~kg}$ with a range of $(20-53 \mathrm{~kg})$. This grip strength was approximately $105.0 \%$ of what value of grip strength was found in the uninjured hand (average, $34.7 \mathrm{~kg}$ ). This result was supposed to be due to the fact that in most cases the fractures occurred in the dominant hand which is inherently strong in an individual.

The complications like joint stiffness (wrist joint stiffness, metacarpophalangeal and interphalangeal joint stiffness), loss of reduction, rotational instability, malunion, prolonged immobilization which are more common in conservative treatment, can be avoided using locking plate fixation for metacarpal fractures.

In our study, the relation of age, sex, and duration of surgery are not statistically significant with functional outcome. Michigan hand outcome questionnaire score with age ( $p$ value- 0.208), sex ( $p$ value- 0.361 ) and duration of surgery ( $\mathrm{p}$ value- 0.403 ). In our study complication rates were $15.6 \%$. Fusetti et al did their research on complication rates after metacarpal plate fixation and they reported that $15 \%$ of their patients had difficulty with fracture healing, $10 \%$ had stiffness while $8 \%$ had plate loosening or breakage, 2 patients had complex regional pain syndrome and 1 patient developed a deep infection. ${ }^{21}$ In other studies, superficial infections occur anywhere from $12-15 \%$ of the time.$^{13,22}$ Deep infections are relatively rare in literature, with reports ranging from $1-9 \% .{ }^{23}$ Compared with other studies found in literature, the incidence of complications like stiffness, complex regional pain syndrome remains the same as in 
our study. In our study, there were no cases reported with serious complications like neuro-vascular injury, implant failure/plate breakage, deep seated infections, heterotopic ossification.

\section{CONCLUSION}

Inspired by our study we conclude that open reduction and internal fixation of fracture metacarpal with mini locking plate is one of the better options that produces rigid and stable fixation. Together with early mobilization, it produces excellent clinical and functional outcomes. Our study had the drawbacks that we didn't had any control group, as well as a smaller number of participants in the study. However considering the availability of only a few research data in literature at present on clinical and functional results after locking plate application for fractures of metacarpal bones, we consider our results to be significant.

Funding: No funding sources

Conflict of interest: None declared

Ethical approval: The study was approved by the institutional ethics committee

\section{REFERENCES}

1. Hove LM. Fractures of the Hand. Scandinavian J Plastic Reconstructive Surg Hand Surg. 1993;27(4):317-9.

2. Chung KC, Spilson SV. The frequency and epidemiology of hand and forearm fractures in the United States. J Hand Surg Am. 2001;26(5):908-15.

3. James JI. Fractures of the proximal and middle phalanges of the fingers. Acta Orthopaedica Scandinavica. 1962;32(1-4):401-12.

4. Black D, Mann RJ, Constine R, Daniels AU. Comparison of internal fixation techniques in metacarpal fractures. J Hand Surg. 1985;10(4):46672.

5. Wong TC, Ip FK, Yeung SH. Comparison between percutaneous transverse fixation and intramedullary $\mathrm{K}$-wires in treating closed fractures of the metacarpal neck of the little finger. J Hand Surg. 2006;31(1):61-5.

6. Ochman S, Doht S, Paletta J, Langer M, Raschke MJ, Meffert RH. Comparison between locking and non-locking plates for fixation of metacarpal fractures in an animal model. J Hand Surg. 2010;35(4):597-603.

7. Chung KC, Pillsbury MS, Walters MR, Hayward RA. Reliability and validity testing of the Michigan Hand Outcomes Questionnaire. J Hand Surg. 1998;23(4):575-87.

8. Lambotte A. Contribution a la chirurgie conservatrice de la main doms les traumatismes. Arch Franco Belges Chir. 1928;31:759-61.
9. Lieber J, Härter B, Schmid E, Kirschner HJ, Schmittenbecher PP. Elastic stable intramedullary nailing (ESIN) of pediatric metacarpal fractures: experiences with 66 cases. European J Ped Surg. 2012;22(04):305-10.

10. Blazar PE, Leven D. Intramedullary nail fixation for metacarpal fractures. Hand clinics. 2010;26(3):3215.

11. Ozer K, Gillani S, Williams A, Peterson SL, Morgan S. Comparison of intramedullary nailing versus plate-screw fixation of extra-articular metacarpal fractures. J Hand Surg. 2008;33(10):1724-31.

12. Foucher G. Bouquet osteosynthesis in metacarpal neck fractures: a series of 66 patients. J Hand Surg. 1995;20(3):86-90.

13. Mohammed R, Farook MZ, Newman K. Percutaneous elastic intramedullary nailing of metacarpal fractures: surgical technique and clinical results study. J Orthop Surg Res. 2011;6(1):37.

14. Hong SJ, Lee HJ, Kim JY, Eo SR, Cho SH. K-wire breakage during metalware removal due to a defective K-wire shaft. Arch Plastic Surg. 2013;40(5):655-7.

15. Crawford GP. Screw fixation for certain fractures of the phalanges and metacarpals. JBJS. 1976;58(4):487-92.

16. Parsons SW, Fitzgerald JA, Shearer JR. External fixation of unstable metacarpal and phalangeal fractures. J Hand Surg [Br]. 1992;17:151-5.

17. Shehadi SI. External fixation of metacarpal and phalangeal fractures. J Hand Surg. 1991;16(3):54450.

18. Schuind F, Cooney WP III, Burny F, An K-N. Small external fixation devices for the hand and wrist. Clin Orth. 1993;293:77-82.

19. Zhu H, Xu Z, Wei H, Zheng X. Locking Plate Alone versus in Combination with Two Crossed Kirschner Wires for Fifth Metacarpal Neck Fracture. Scientific Rep. 2017;7:46109.

20. Bohannon RW. Dynamometer measurements of hand-grip strength predict multiple outcomes. Perceptual Motor Skills. 2001;93(2):323-8.

21. Fusetti C, Meyer H, Borisch N, Stern R, Santa DD, Papaloizos M. Complications of plate fixation in metacarpal fractures. J Trauma. 2002;52(3):535-9.

22. Sletten IN, Nordsletten L, Husby T, Ødegaard RA, Hellund JC, Kvernmo HD. Isolated, extra-articular neck and shaft fractures of the 4th and 5th metacarpals: a comparison of transverse and bouquet (intra-medullary) pinning in 67 patients. $\mathrm{J}$ Hand Surg. 2012;37(5):387-95.

23. Souer JS, Mudgal CS. Plate fixation in closed ipsilateral multiple metacarpal fractures. J Hand Surg. 2008;33(6):740-4.

Cite this article as: Kandasamy AA, Pheroz M, Kumar A, Krishna LG, Jain A, Grower R. Fractures of metacarpal bone: evaluation of functional outcome of open reduction and internal fixation with mini locking plate: a hospital based study. Int J Res Orthop 2019;5:519-25. 